\title{
Using virtual reality simulated implantation for fit-testing pediatric patients for adult ventricular assist devices
}

Ryan R. Davies, MD, ${ }^{\mathrm{a}}$ Tarique Hussain, MD, ${ }^{\mathrm{b}}$ and Animesh Tandon, MD, ${ }^{\mathrm{b}}$ Dallas, Tex

From the Departments of ${ }^{\mathrm{a} C}$ Cardiovascular and Thoracic Surgery and ${ }^{\mathrm{b}}$ Pediatrics and Radiology, UT Southwestern Medical Center and Children's Health, Dallas, Tex.

Disclosures: Drs Tandon and Hussain have significant ownership interests in VARYFII Imaging. Dr Davies reported no conflicts of interest.

The Journal policy requires editors and reviewers to disclose conflicts of interest and to decline handling or reviewing manuscripts for which they may have a conflict of interest. The editors and reviewers of this article have no conflicts of interest.

Received for publication Oct 15, 2020; accepted for publication Oct 20, 2020; available ahead of print Oct 24, 2020 .

Address for reprints: Ryan R. Davies, MD, Children's Medical Center Dallas, 1935 Medical District Dr, MC B3.410, Dallas, TX 75235 (E-mail: ryan.davies@utsouthwestern.edu).

JTCVS Techniques 2021;6:134-7

2666-2507

Copyright (C) 2020 The Authors. Published by Elsevier Inc. on behalf of The American Association for Thoracic Surgery. This is an open access article under the CC BY-NC-ND license (http://creativecommons.org/licenses/bync-nd/4.0/).

https://doi.org/10.1016/j.xjtc.2020.10.017

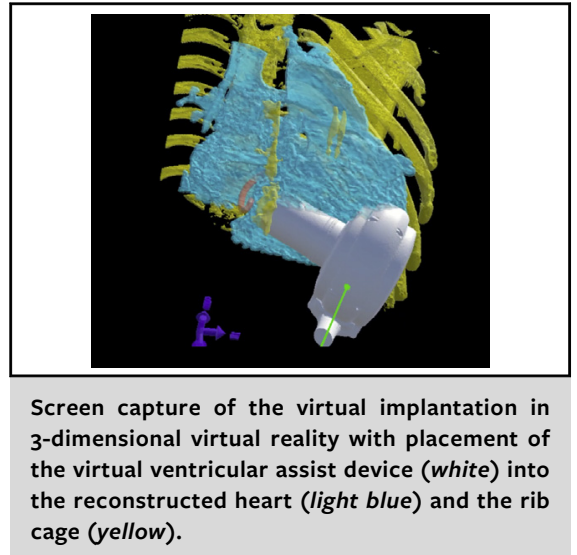

CENTRAL MESSAGE

Virtual implantation of adult intracorporeal devices into children enables successful implantation and use in small children.

See Commentaries on pages 138, 140, and 142
Technological advancements in ventricular assist device (VAD) support have resulted in progressive decreases in device size. This has allowed centers to push the lower limits of size for use in pediatric patients. ${ }^{1,2}$ These limits remain uncertain, however. Although the use of virtual implantation has been described with a total artificial heart in smaller adult patients, ${ }^{3}$ the application to pediatric patients undergoing systemic VAD implantation is less clear.

We have used virtual reality (VR) simulated implantation from 3-dimensional (3D) reconstruction of cross-sectional imaging (either cardiac magnetic resonance imaging or computed tomography scans) to evaluate intrapericardial placement of the HeartWare VAD (HVAD; Medtronic, Dublin, Ireland) and the HeartMate3 (Abbott, Chicago, Ill) intrapericardial pumps in children. Our criteria for a pump "fitting" is that the tip of the pump inflow lies below the atrioventricular (AV) valve annulus (fully within the ventricle) when the pump is placed inside the chest wall. This should preserve AV valve function and result in less distortion of cardiac structures, which may be especially important when trying to preserve right ventricular function on VAD support.

We provide 3 images of similar-sized children (patient 1: $17 \mathrm{~kg}, 0.67 \mathrm{~m}^{2}$ with a single systemic right ventricle; patient 2: $14.3 \mathrm{~kg}, 0.66 \mathrm{~m}^{2}$ with dilated cardiomyopathy; patient 3 : $14.6 \mathrm{~kg}, 0.65 \mathrm{~m}^{2}$ with pacemaker-induced cardiomyopathy following repair of an AV septal defect and mechanical left AV valve replacement). Despite being heavier than the other 2 patients, patient 1 had the shortest distance between the AV valve and chest wall ( $\sim 5 \mathrm{~cm}$ vs $\sim 7 \mathrm{~cm}$ ) (Figure 1$)$. Patients 2 and 3 underwent successful HVAD implantation (Figure 2). Patient 1 was not felt to be a candidate for HVAD implantation, because during VR placement of the pump within the chest, the pump inflow would have been located within the system AV valve annulus. She had an extracorporeal device placed instead.

VR implantation allows for a more accurate assessment of pump position within the chest, including the angle of the inflow cannula toward the AV valve, the impact of chest wall anatomy, and the relationship between the $3 \mathrm{D}$ volume of the pump and the dimensions of the ribcage (Figure 3, Videos 1 and 2). This has informed the location of pump fixation to the chest wall (which we commonly perform in smaller patients). Virtual fit-testing has enabled successful implantation of the HeartMate 3 in 2 of the smallest patients described in the literature to date (both with a body surface area $<.8 \mathrm{~m}^{2}$ ), as well as one of the smallest HVAD patients $(14.3 \mathrm{~kg})$. 

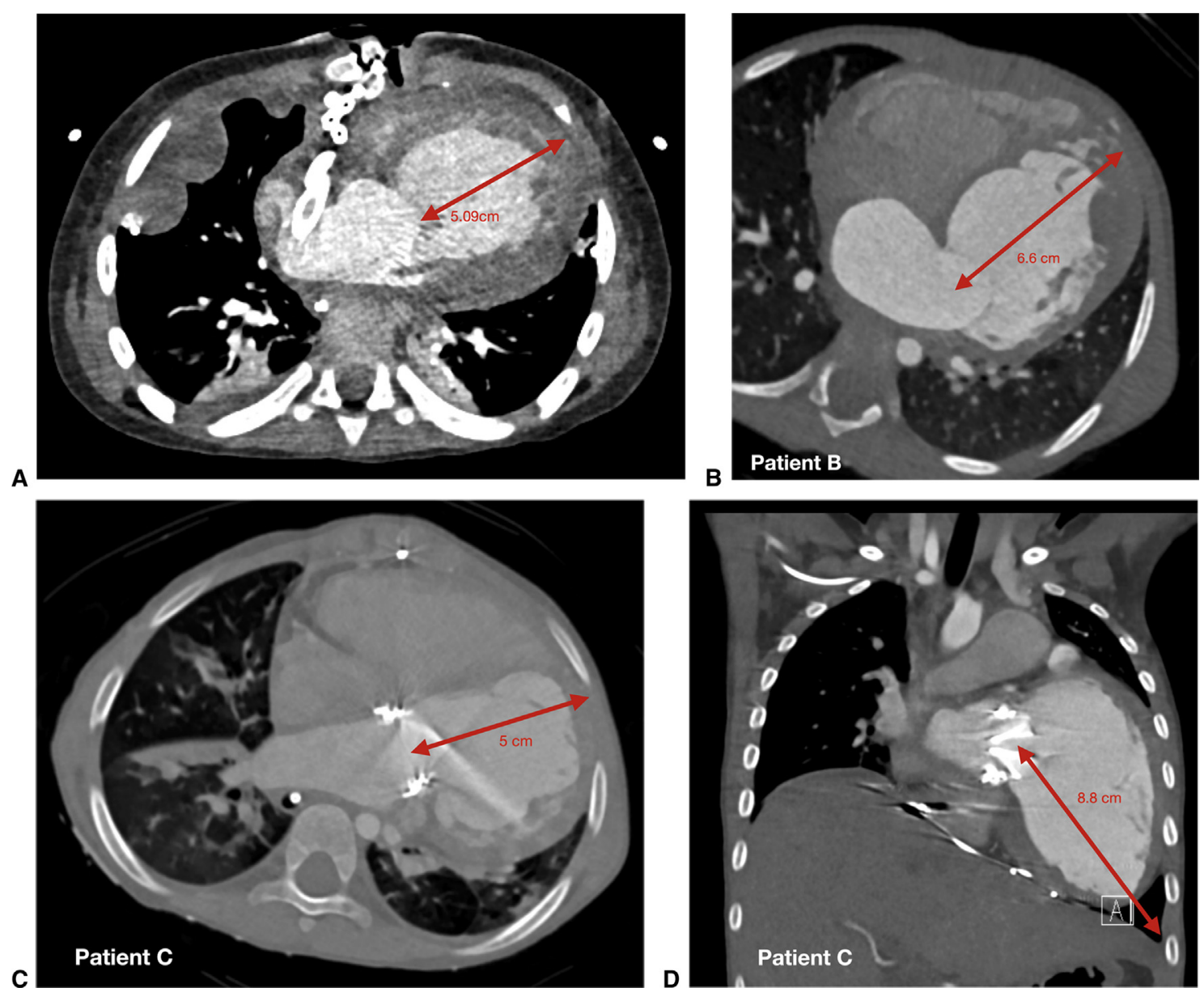

FIGURE 1. Representative slices from computed tomography scans illustrating that despite the similar body surface area of the 3 patients, 3 -dimensional (3D) thoracic anatomy can differ substantially. A, The distance is shortest in patient 1, despite greater weight, similar body surface area, and a single ventricle circulation, which usually increases available space due to the hypoplastic ventricle. B, Patient 2 has more space between the chest wall and the annulus in the axial plane. $\mathrm{C}$ and $\mathrm{D}$, The importance of $3 \mathrm{D}$ reconstruction and virtual reality (VR) fit-testing is illustrated in patient 3 , in whom the axial distance is relatively short (C), but the distance on coronal imaging (D) is much longer. These images are representative, but VR fit-testing enables allows for more accurate and precise positioning of the pump within the chest wall to assess the position of the inflow cannula in relation to the atrioventricular valve and systemic outflow. With VR fit-testing, the pump can be rotated in all dimensions (as opposed to being limited by the axes of the cross-sectional imaging) to identify a position with sufficient space for placement.
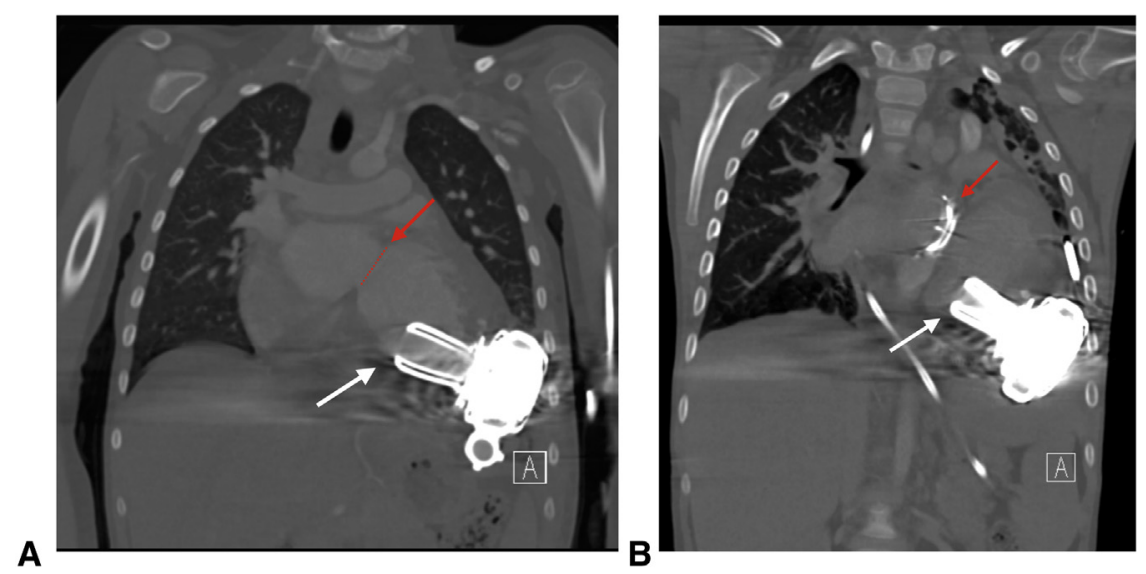

FIGURE 2. Coronal cross-sectional imaging of patient 2 (A) and patient 3 (B). The tip of the ventricular assist device (VAD) inflow cannula is indicated by the white arrow. The position of the left atrioventricular valve annulus is indicated by the red arrow and either the dashed red line in the native valve annulus (A) or the radioopaque mechanical valve prosthesis (B). In both cases, there is sufficient room between the inflow to the VAD and the annulus. 

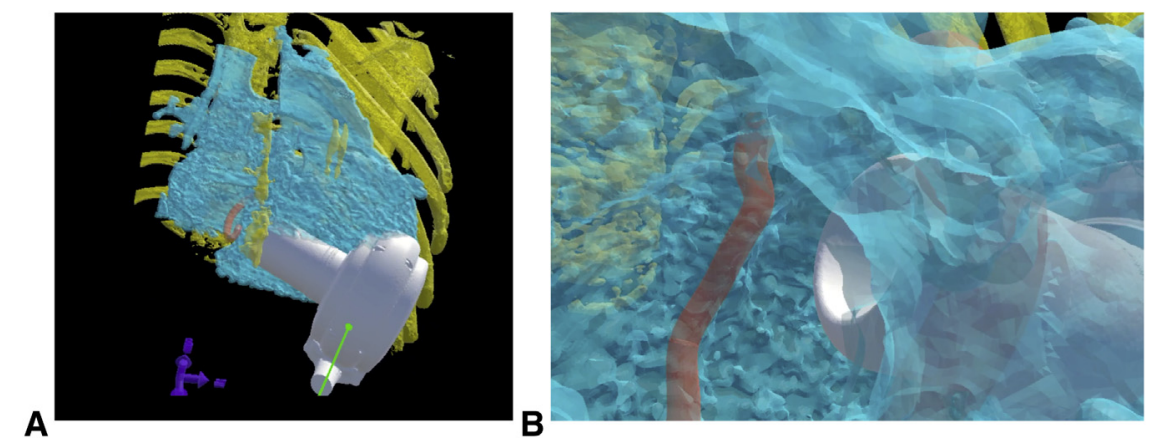

FIGURE 3. Screen captures of the virtual implantation in 3-dimensional (3D) virtual reality (VR). The fit-testing is performed in 3D VR space using an HTC Vive virtual reality headset (HTC, Taoyuan City, Taiwan) and I2I (Imager to Interventionalist) virtual reality software (VARYFII Imaging, Dallas, Tex). Shown are 2-dimensional (2D) screen captures of the live 3D fitting process to demonstrate the components present in the VR space. A, Placement of the virtual ventricular assist device (VAD; white) into the reconstructed heart (light blue) and rib cage (yellow) of patient A. B, View of the tricuspid valve annulus (red) within the heart (light blue) and VAD (white).

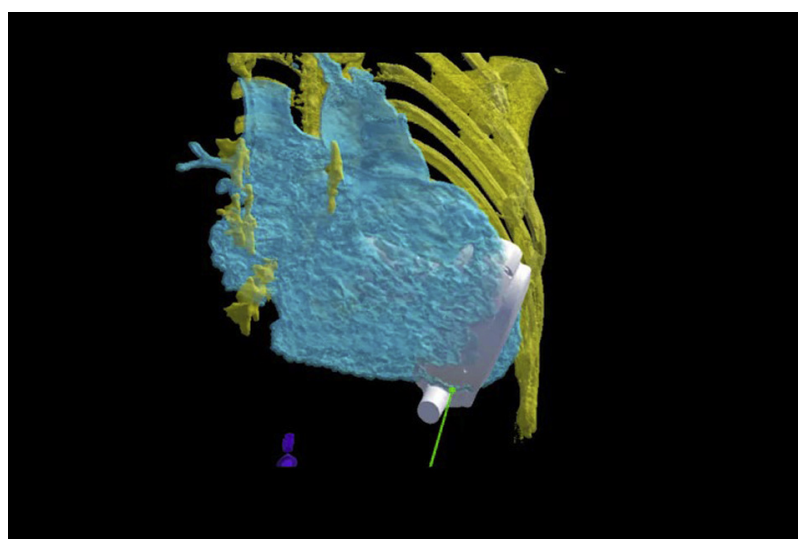

VIDEO 1. Two-dimensional video of virtual fit-testing with simultaneous audio commentary and explanation. The heart is reconstructed using a shell placed around the blood pool on cross-sectional imaging. This allows for visualization of the cardiac chambers and some assessment of the location of large trabeculations, which can be especially useful in systemic right ventricles. Colors are applied to the reconstructed image to assist with placement. The shell around the blood pool is light blue, the rib cage is yellow, and the atrioventricular (AV) valve annulus is shown in red. Surgical implantation will displace the ventricle from the chest wall and rib cage, so the implantation cannot determine the precise positioning of the device within the ventricle. However, we view the position of the AV valve annulus as relatively immobile in the short term and place a premium on preserving systemic AV valve function whenever possible. Therefore, by placing the $\mathrm{VAD}$ within the rib cage in a position with the inflow directed at the $\mathrm{AV}$ valve and clear of the largest trabeculations, we are able to assess the distance between the annulus and the tip of the inflow. Video available at: https://www.jtcvs.org/article/S2666-2507(20)30597-6/fulltext.

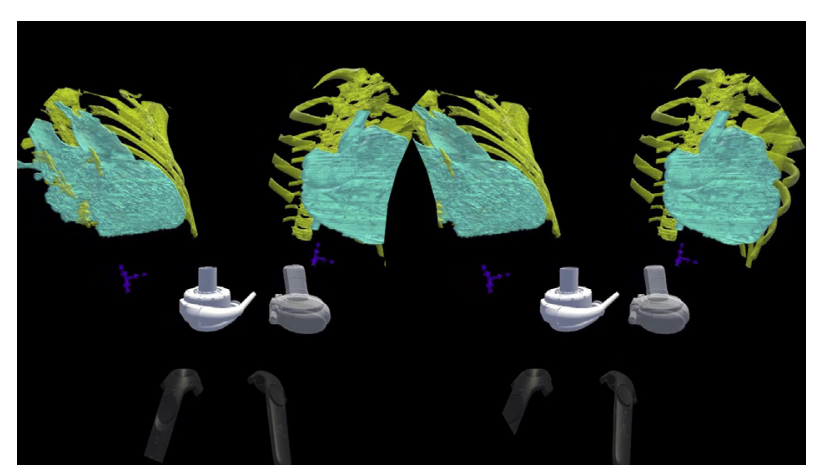

VIDEO 2. Three-dimensional video of virtual fit-testing with simultaneous audio commentary and explanation. The heart is reconstructed using a shell placed around the blood pool on cross-sectional imaging. This allows for visualization of the cardiac chambers and some assessment of the location of large trabeculations, which can be especially useful in systemic right ventricles. Colors are applied to the reconstructed image to assist with placement. The shell around the blood pool is light blue, the rib cage is yellow, and the atrioventricular (AV) valve annulus is shown in red. Surgical implantation will displace the ventricle from the chest wall and rib cage, so the implantation cannot determine the precise positioning of the device within the ventricle. However, we view the position of the AV valve annulus as relatively immobile in the short term and place a premium on preserving systemic AV valve function whenever possible. Therefore, by placing the VAD within the rib cage in a position with the inflow directed at the AV valve and clear of the largest trabeculations, we are able to assess the distance between the annulus and the tip of the inflow. Video available at: https://www.jtcvs.org/article/S2666-2507(20) 30597-6/fulltext. 
The need for informed consent regarding the publication of the study data was waived by the UT Southwestern Medical Center's Institutional Review Board.

\section{References}

1. O'Connor MJ, Lorts A, Davies RR, Fynn-Thompson F, Joong A, Maeda K, et al. Early experience with the Heartmate 3 continuous-flow ventricular assist device in pediatric and congenital heart disease patients: a multi-center registry analysis. $J$ Heart Lung Transplant. 2020;39:573-9.

2. Conway J, Miera O, Adachi I, Maeda K, Eghtesady P, Henderson HT, et al; Investigators PVAD. Worldwide experience of a durable centrifugal flow pump in pediatric patients. Semin Thorac Cardiothorac Surg. 2018;35:679-81.

3. Ferng AS, Oliva I, Jokerst C, Avery R, Connell AM, Tran PL, et al. Translation of first North American 50 and $70 \mathrm{cc}$ total artificial heart virtual and clinical implantations: utility of 3D computed tomography to test fit devices. Artif Organs. 2016; 41:727-34. 